\title{
Some Peculiarities of Registration of Pharmaceutical Trademarks ${ }^{1}$
}

\section{目 Vironika Pilyugina}

Senior Associate, Hogan Lovells CIS, trademark attorney. Address: 22 Tverskaya Str., Moscow, 125009, Russia. E-mail: vironika.pilyugina@hoganlovells.com

\section{Alexandra Bakhtiozina}

Trainee lawyer, Hogan Lovells CIS. Address: 22 Tverskaya Str., Moscow, 125009, Russia. E-mail: alexandra.bakhtiozina@hoganlovells.com

\section{㴟目 Abstract}

The number of cases where pharmaceutical trademarks are the subject of proceedings has skyrocketed in recent years. It evidences the relevance of an analysis of the peculiarities of trademark protection in relation to pharmaceutical trademarks, which is presented in the article. Close attention is paid to an analysis of registration of designations identical to INN or derivatives from INN in the Russian Federation. Relying on analysis of the practice of the Chamber for Patent and Trademark Disputes and courts, the authors conclude that designations identical to INN are unable to benefit from trademark protection as non-distinctive and contradictory to public interests. As to designations comprising or resembling INN to some extent, such designations have chances to be registered as trademarks if they are not considered as INN derivatives. A trademark is recognized as an INN derivative if it is similar to INN to the degree of confusion. Ultimately, the authors reach the conclusion that current Russian legislation does not require any amendments to enhance practice on consideration of cases where designations identical or confusingly similar to INN are involved, since such cases can be successfully inserted into general provisions governing trademarks. Another issue which is also examined in the article is the current approach of the Chamber for Patent and Trademark Disputes and courts to the assessment of similarity in relation to pharmaceutical trademarks, especially the practice of applying the so-called «Three Letter Rule». The authors hold the view that prioritization of the «Three Letter Rule» is a negative trend, since following the «Three Letter Rule» blindly cannot replace due assessment of the designation. The authors attempt to prove this by providing examples of flaws inherent in situations including the «Three Letter Rule."

\section{O-n 目 Keywords}

Trademarks, Pharmaceutical trademark, Registration, Rospatent, Three Letter Rule, INN.

Citation: Pilyugina V., Bakhtiozina A. (2016) Some Peculiarities of Registration of Pharmaceutical Trademarks. Pravo. Zhurnal Vysshey shkoly ekonomiki, no 2, pp. 135-142 (in English).

DOI: $10.17323 / 2072-8166.2016 .2 .135 .142$

\section{Introduction}

Rivers of ink have been spilled to show the importance of the asset of a trademark. We would spill a few more drops to indicate the importance of trademark protection for pharma-

${ }^{1}$ The views expressed are the personal views of the authors. The article is not intended to reflect the position of Hogan Lovells CIS on relevant matters. 
ceutical companies. Indeed, when a patent for a new medicine expires and generics penetrate the market, a trademark becomes crucial to maintain competitive advantage ${ }^{2}$. Under such circumstances, questions on trademark protection and trademark enforcement inevitably come to the foreground.

In practice to succeed with trademark registration for pharma-related goods ${ }^{3}$ and further enforcement of trademark rights, a wide range of useful tips should be taken into account. Most of them have been formed by the decisions of the Chamber for Patent and Trademark Disputes under Russian PTO (hereinafter - Chamber) ${ }^{4}$ and Arbitrage (State Commercial) Courts.

That is why nowadays even detailed knowledge of the regulatory maze is insufficient without following current trends adhered to by the Chamber and the courts.

This article aims to analyze the approaches of the Chamber and the courts to such issues as (1) possibility of registration of International Nonproprietary Name (INN) or a designation comprising or resembling INN as a trademark and (2) determination of the likelihood of confusion of the pharmaceutical trademarks. Specifically, the article examines the application of the so-called "Three Letter Rule" and presents the authors' speculations on the risk of its application.

\section{Registration of a Designation Identical to an International Nonproprietary Name (INN)}

According to the World Health Organization (hereinafter - WHO), an international nonproprietary name (hereinafter - INN) is an official generic name given to a pharmaceutical substance or active substance ingredient. The initial goal to introduce INNs was by providing a unique standard name for each active ingredient to simplify communications between medical practitioners and scientists and to enhance clarity of identification, safe prescription and dispensing of medicines to patients ${ }^{5}$. Such an explanation was almost replicated in the Methodical Recommendations on the Rational Choice of Drug Names, adopted by the Ministry of Health of the Russian Federation ${ }^{6}$.

The WHO declared that INN is a public property of sorts, and therefore may be used without any restrictions whatsoever to identify pharmaceutical substances without being appropriated in any way.

In May 1993 the World Health Assembly Resolution No. WHA 46.19 was adopted, under which the member-states of the WHO are obliged to hinder the undue use of INNs or derivatives from INNs. The Resolution of 115 Session of the WHO Executive Board No. EB115.R4 confirmed the above obligation of the member-states and went even further. It clearly states the need to prevent the acquisition of exclusive rights to INN and to prohibit the registration

${ }^{2}$ Brennan H. The Cost of Confusion: The Paradox of Trademarked Pharmaceuticals, 22 Mich. Telecomm. \& Tech. L. R. 1 (2015). P. 18. Available at: http://repository.law.umich.edu/mttlr/vol22/iss1/1 (accessed: 10.04.2016)

${ }^{3}$ Further in the article under "pharmaceutical trademarks» the authors mean trademarks registered in relation to pharmaceutical goods included in class 5 of the International Classification of Goods and Services (established by the Nice Agreement (1957)).

${ }^{4}$ The decisions are signed by the Head of Rospatent and made on the basis of the Chamber's opinion. Therefore, de jure, Rospatent makes the decisions, but, de facto, the decisions are made by the Chamber. We will employ the term "Chamber's decisions" to the detriment of accuracy, but for the benefit of comprehension.

${ }^{5}$ Guidelines on the Use of INNs for Pharmaceutical Substances (1997), P. 5-6. Available at: http://apps.who. int/iris/bitstream/10665/63779/1/WHO_PHARM_S_NOM_1570.pdf (accessed: 10.04.2016)

${ }^{6}$ Rational Choice of Drug Names. Methodical Recommendations (adopted by the Ministry of Health and Social Development of the Russian Federation on October 10, 2005). 
of INNs and their derivatives as trademarks. However, respective WHO resolutions may not be considered as a part of the Russian legal system, according to Article 15 of the Constitution of the Russian Federation. Thereby formally, the above provisions may not serve as legal grounds for refusal of registration of INN as a trademark ${ }^{7}$.

Such a state of affairs has resulted in a deadlock. For example, a company files an application with the Russian PTO (Rospatent) to register INN as a trademark. Obviously, if INN is protected as a trademark, it would limit the freedom of further use of this INN by other pharmaceutical manufacturers. However, on what grounds should Rospatent refuse the registration of such a trademark?

The absence of a separate prohibition to register a designation identical to INN in the Civil Code of the Russian Federation (hereinafter - RCC) forces the examiners to select a ground for refusal amongst those listed in Part IV of the RCC. In practice, it is recognised that a designation identical to INN does not possess distinctiveness, and thereby may not be registered as a trademark based on Paragraph 1 of Article 1483 of the RCC (Paragraph 1 of Article 6 of the Law "On Trademarks, Service Marks and Appellation of Origin of Goods" in cases when a trademark was registered before the entry date of Part IV of the $\mathrm{RCC}^{8}$ ).

The same fate befell designations executed in the form of INN + weak elements like PLUS, TURBO, etc."'. It seems absolutely justified, because in such cases the word element representing INN is dominant, while the weak elements do not change the perception of the designation as a whole. Therefore, such designations may not enjoy protection as trademarks.

However, the situation not so straightforward when a designation comprising or resembling INN is applied for registration.

\section{Registration of a Designation Comprising or Resembling INN}

An online search of the Rospatent database revealed quite a large amount of trademarks including INN as part of a registered trademark, or resembling INN to some extent. However, there are also cases where such registrations were subsequently cancelled before the Chamber. An analysis of the decisions of the Chamber shows that the predominant grounds for cancellation are as follows:

1. Lack of a distinctive character of the trademark (Paragraph 1 of Article 1483 of the RCC);

2. Misleading character of the trademark (Paragraph 3 (1) of Article 1483 of the RCC);

3. Contradiction to public interests (Paragraph 3 (2) of Article 1483 of the RCC);

The inconsistency of practice in terms of grounds for refusal in protection of designations similar to INN is not the issue. The issue is that though the Chamber and the courts realise that a designation too similar to INN may not be registered as a trademark, there are no direct provisions in Russian law prohibiting such registration. As mentioned earlier, reference to WHO regulations may not be a remedy in this instance.

\footnotetext{
${ }^{7}$ Robinov A.A. Novoe v praktike Vischego Arbitrazhnogo Suda Rossiiskoy Federatsii Imyshestvennie otnoshenia v Rossiiskoy Federatsii, 2013, No. 8 [New in the practice of the Higher Arbitrazh Court of the Russian Federation, Property Relationship, 2013, No. 8]

${ }^{8}$ Law of the Russian Federation of 23 September 1992 No. 3520-1 "On Trademarks, Service Marks and Appellation of Origin of Goods" (The document is no longer valid since 1 January 2008 in connection with the adoption of the Federal Law of 18 December, 2006 No. 231-FZ)

${ }^{9}$ Chamber's opinion, 9 December 2010 (Addendum to Rospatent's decision of 27 December 2010 on application No. 2004710121/50); Chamber's opinion, 15 August 2012 (Addendum to Rospatent's decision of $31 \mathrm{Au}$ gust 2012 on application No. 2010735526).
} 
If there are no questions on whether INN is non-distinctive for the goods of Class 5 of the Nice Classification, the question arises whether it is legally correct to consider comprising or resemblance to INN designations as non-distinctive, misleading or contradictory to public interests?

Luckily for the pharmaceutical industry, the Higher Arbitrage Court put a halt to such turmoil in its ruling regarding the KARTINON trademark.

The trademark for KARNITON was successfully registered in relation to, inter alia, pharmaceutical products. A third party initiated a cancellation action against the KARNITON trademark before the Chamber, claiming that KARNITON is confusingly similar to INN "Karnitin", and therefore the registration for KARNITON has almost deprived other pharmaceutical manufacturers of the possibility of using "Karnitin" due to the risk of violation of KARTINON's trademark rights.

The Chamber upheld the trademark registration. Furthermore the court of the first instance, the court of appeal and the court of cassation (second) appeal sustained the decision of the Chamber and kept the registration for KARNITON in force.

Nevertheless, the Higher Arbitrage Court overruled the rulings of the lower courts and cancelled the trademark registration for KARTITON with respect to goods of Class 5 of Nice Classification $^{10}$. The Higher Arbitrage Court stated that registration of INN or its derivatives as a trademark is prohibited, since INN constitutes a generic term, and hence is non-distinctive. It is noteworthy the Court stipulated that such registration may be contradictory to public interests and the right to health protection and medical care as guaranteed by Article 41 of the Constitution of the Russian Federation.

It is worth mentioning that the Higher Arbitrage Court based its position on WHO Resolutions, the Order of Rospatent on the use of the database of INN ${ }^{11}$ and the Methodical Recommendations on rational choice of drug names as well as on the fact that the use of INN is mandatory for pharmaceutical manufacturers under several legislative acts of the Russian Federation $^{12}$.

The respective ruling of the Court mentioned has become a pivotal point in laying the foundation of a new practice of more detailed examination of applications for pharmaceutical trademarks and more thoughtful consideration of cases where pharmaceutical trademarks are involved. The respective ruling set in stone that a designation identical to INN cannot be protected as a trademark in the Russian Federation and provided additional guidelines for analysis of the designations comprising INN or resembling INN.

In accordance with the Higher Arbitrage Court, if a designation is confusingly similar to INN, it shall be treated as an INN derivative. As we have mentioned, the WHO documents discourage granting trademark protection not only to INN, but also to its derivatives, but before the aforementioned ruling it was not clear what INN derivatives are.

The Court considered KARNITON as confusingly similar to "Karnitin" based on visual and phonetic criteria and overall association with INN, despite slight differences. That was a reason to consider it as an INN derivative and cancel the trademark registration for KARNITON in relation to goods of Class 5 of the Nice Classification.

${ }^{10}$ The Ruling of Presidium of the Higher Arbitrage Court of 28 February 2012 No. 12436/11 on case No. A40-66999/10-26-563.

${ }^{11}$ The Order of Rospatent of 4 April 2008 No. 45 "On the Use of Database of International Nonproprietary Names (INN)".

${ }^{12}$ Indeed, pharmaceutical manufacturers are obliged to use INN, for example, according to provisions of the Federal Law of 12 April 2010 No. 61-FZ "On Circulation of Drugs". 
To summarize, the Higher Arbitrage Court set forth that (1) designations identical to INN are unable to benefit from trademark protection due to lack of distinctiveness and contradiction to public interests, (2) designations comprising or resembling INN can be protected as trademarks only if they do not derive from INN, (3) a trademark is recognized as a derivative from INN if it is similar to INN to the degree of confusion.

Such an approach correlates with the practice of foreign jurisdictions. For instance, the national PTO in Finland takes INNs into consideration in the course of examining trademark applications. Designations that are identical or confusingly similar to INN are considered nondistinctive. The French PTO checks, as a part of the examination process, consider whether an applied designation may cause confusion with existing INNs. If this is the case, the application will be rejected. In Germany, the practice is that INNs may not be registered as trademarks due to lack of distinctiveness ${ }^{13}$.

Stated succinctly, most legislative acts of foreign jurisdictions ${ }^{14}$ do not provide for the direct prohibition of granting trademark protection to designations identical and confusingly similar to INN. PTOs and courts have to insert applications for INN into the general grounds for refusal in trademark protection, such as lack of distinctiveness, similar to the practice in Russia.

The authors are of the opinion that current Russian legislation does not require any amendments to successfully handle cases on designations identical to INN and comprising or resembling INN. In our view, trademark applications for designations identical to INN should be rejected by Rospatent with reference to Paragraph 1 and Paragraph 3 (2) of the Article 1483 of the RCC. As to designations comprising or resembling INN, the decision on granting protection or refusal of registration should be considered depending on the level of fancy character and direct association with INN.

The need to examine applications for comprising or resembling INN designations on a case-by-case basis is explained by the following. It is not necessarily that an application for a designation which comprises or resembles INN aims to monopolize INN and prohibit its use by third parties. Pharmaceutical trademarks are sublimina ${ }^{15}$ and pharmaceutical companies are well aware of this. Frequently, in applying for a trademark comprising or resembling INN, pharmaceutical companies pursue the goal of providing a hint to consumers regarding the active ingredient of the drug. The rationale behind such strategy is that medical practitioners and savvy consumers may be better able to identify the required drugs pursuant to resemblance to the INN included in their trademarks. Therefore, it will contribute to providing more precise information on the offered drugs and facilitate market efficiency ${ }^{16}$.

Thus there is a very thin line between the permissible and impermissible similarity to INN. Consequently, following the aforementioned ruling of the Higher Arbitrage Court, special emphasis should be placed on whether the applied designation is an INN derivative, i.e. is similar to INN to the degree of confusion.

${ }^{13}$ Pharmaceutical Trademarks 2013/2014: Global Guide. Available at: http://www.worldtrademarkreview. com/Intelligence/Pharmaceutical-Trademarks/2013 (accessed: 10.04.2016)

${ }^{14}$ There are examples to the contrary. For example, Section 13 (b) of the Trade Marks Act of India (1999) specifically prohibits trademark registration of words "declared by the World Health Organisation and notified in the prescribed manner by the Registrar from time to time, as an international non-proprietary name or which is deceptively similar to such name".

${ }^{15}$ Herberholz D. Curing Confusion: An Overview of the Regulatory Complexities of Obtaining Pharmaceutical Trademarks and a Prescription for Reform, 8 Minn. J.L. Sci. \& Tech. 97 (2007). P. 123. Available at: http:// scholarship.law.umn.edu/mjlst/vol8/iss $1 / 4$

${ }^{16}$ Brennan H. Op. cit. 


\section{The Three Letter Rule}

According to the current approach in determining whether a pharmaceutical trademark is confusingly similar to INN or not, the Chamber and courts mostly apply standard criteria, as laid down in the Methodical Recommendation on examination of the applied designations on identity and similarity ${ }^{17}$, but also apply the so-called "Three Letter Rule"18.

The "Three Letter Rule" has been introduced by the Methodical Recommendations on rational choice of drug names, adopted by the Ministry of Health of the Russian Federation, which state that:

"when counting letters (characters) that make up the words, the differences between the compared names must be 3 or more letters (characters) in any combination".

However, as highlighted by the Recommendations, it is a general rule which is not a law to be followed strictly.

In practice, Chamber and courts willingly use such a rule in cases where pharmaceutical trademarks are subject to proceedings ${ }^{19}$. In some cases the "Three Letter Rule" was applied as an additional ground ${ }^{20}$. However, there are cases where the "Three Letter Rule" was applied as one of the main arguments ${ }^{21}$.

In our view, prioritization of the "Three Letter Rule" is an extra-negative trend. Following the "Three Letter Rule" blindly may neither replace due assessment of proposed designation on its registration, nor protect the market from mala fide pretensions from the side of the trademark owners. One argument in favour of this is that the length of the designation as a whole makes a significant difference. When the trademark in question consists of 4 or 5 letters, the difference in 3 characters may change the designation sufficiently. However, when the trademark in question consists of 10 or more letters, 3 letters may not be perceptible at all.

The second argument is the position of the letters within the trademark in question. For instance, since most people read from left to right, the first part of the word would always be the dominant one, as it would be more perceptible and memorable for consumers, while the endings are overwhelmingly standard, and therefore most frequently not imprinted on a consumers' memory. Thus when INN and the designation in question coincide by the first part and differ by ending only, the level of similarity is much higher than in a case when endings are

${ }^{17}$ The Order of Rospatent of 31 December 2009 No. 197 "On Adoption of Methodical Recommendation on examination of the applied designations on identity and similarity"

${ }^{18}$ It is relevant not only for determination whether the pharmaceutical is confusingly similar to INN, but also whether one pharmaceutical trademark is similar to another pharmaceutical trademark.

19 The Three Letter Rule is used in a wide range of cases involving pharmaceutical trademarks, including cases when a pharmaceutical trademark and INN or a pharmaceutical trademark and another pharmaceutical trademark collide. For instance, Chamber's opinion, 15 July 2015 (Addendum to Rospatent's decision, 31 July 2015 on application No.2013711497); Chamber's opinion,16 March 2015 (Addendum to Rospatent's decision, 29 May 2015 on application No. 2013704992); Chamber's opinion, 12 November 2014 (Addendum to Rospatent's decision, 26 January 2015 on application No. 2011735887); Chamber's opinion, 19 June 2014 (Addendum to Rospatent's decision, 30 June 2014 on application No.0001101490).

${ }^{20}$ Chamber's opinion, 16 March 2015 (Addendum to Rospatent's decision, 29 May 2015 on application No. 2013704991); Chamber's opinion, 22 December 2014 (Addendum to Rospatent's decision, 30 March 2015 on application No. 2013704111).

${ }^{21}$ Chamber's opinion, 30 January 2009 (Addendum to Rospatent's decision, 11 March 2009 on application No. 2006705134/50) 
similar and the first parts are different. An exception may be in a case where the first part of the invented designation constitutes a prefix, while the ending is a stem, forming INN.

One more argument against the implicit application of the "Three Letter Rule" is that amending 3 letters may not make a significant difference in cases where such letters are silent (aphonic). Indeed, the consumer does not only visually perceive the designation, but also the orientation on pronunciation. Thus the phonetic criteria should not be underestimated.

The list of grounds confirming the non-applicability of the "Three Letter Rule" may be continued, but even the abovementioned examples show clearly that a formal application of the "Three Letter Rule" may render the examination inaccurate. Therefore a plethora of cases where the "Three Letter Rule" does not work are evidence that the Chamber and the courts should proceed with caution in applying the respective rule, and always be mindful that each case requires a thoughtful analysis of the compared designations.

The following case is an outstanding example of a meticulous analysis of pharmaceutical trademarks. The owner of the trademark for “ТЕТРАЛГИН ТЕTRALGINUM» initiated a cancellation action against a trademark for «САНТОТИТРАЛГИН SANTOTITRALGIN», indicating the similarity of the trademarks and the risk of consumer confusion. Notwithstanding that the difference between the compared designations is more than 3 letters, the trademark for «САНТОТИТРАЛГИН SANTОТITRALGIN» was cancelled. The Chamber stated that SANTOTITRALGIN is a compound word, and therefore cannot be pronounced in one breath. This involves a logical pause between the SANTO and TITRALGIN parts. Since TITRALGIN and TETRALGINUM are similar, the part SANTO pronounced separately and ending -UM does not affect the perception of the designation, the compared designations "ТЕТРАЛГИН TETRALGINUM» and «САНТОТИТРАЛГИН SANTOTITRALGIN» are considered to be confusingly similar ${ }^{22}$.

We see that the "Three Letter Rule" was not applied, even with respect to the dominant part of the designation (TETRALGINUM and TITRALGIN). Instead, a complex analysis of the designations was made. This approach is estimated by us as beneficial for the further development of practice.

\section{Conclusion}

A trademark is an extremely important asset for pharmaceutical companies. After the expiration of a patent, trademark rights play a crucial role in guarding and extending a company's market share ${ }^{23}$. At first glance it might seem that from a public health perspective it would be better for drugs to be marked by their INNs. Indeed, it may be quite simple to choose the right medicine if it is marked by INN only. However, in this case it would be much more complicated for a consumer to distinguish the manufacturer and choose the only one with a quality he trusts. In such an environment, pharmaceutical companies need to invest heavily in brand recognition and brand protection.

In such circumstances, it is important to choose the right means of individualization which would be at the permissible level of association with INN and still possess necessary level of inventiveness. Therefore it shall be taken into account that a designation identical to INN would be considered non-distinctive and contradictory to public interests, whilst designations com-

\footnotetext{
${ }^{22}$ Chamber's opinion, 24 November 2010 (Addendum to Rospatent's decision, 24 February 2011 on application No. 2006730266/50)

${ }^{23}$ Brennan H. Op. cit.
} 
prising or resembling INN may have a chance for registration, if they are not considered to be derivatives from INN.

Pharmaceutical companies should also be aware that in the course of assessing the likelihood of confusion, the Chamber and the courts would normally apply the "Three Letter Rule" apart from standard criteria. An analysis shows that the "Three Letter Rule", when applied single-handedly, is flawed in many situations. Therefore it should be an additional tool which supplements, but does not replace due assessment of similarity of the marks from the perspective of consumer perception.

\section{D国 References}

Brennan H. (2015) Cost of Confusion: The Paradox of Trademarked Pharmaceuticals, 22 Mich. Telecomm. \& Tech. L. Rev. 1. Available at: http://repository.law.umich.edu/mttlr/vol22/iss1/1

Ferrand L., New B. (2003) Syllabic length effects in visual word recognition and naming. Acta Psychol, vol. 113 , p. $167-183$

Herberholz D. (2007) Curing Confusion: An Overview of the Regulatory Complexities of Obtaining Pharmaceutical Trademarks and a Prescription for Reform, 8 Minn. J.L. Sci. \& Tech. 97. Available at: http://scholarship.law.umn.edu/mjlst/vol8/iss1/4 (accessed: 10.04.2016)

Jagla F., Umansky B. (2009) Naming the Product: The Intersection of FDA and Trademark Law, IP Litigator, vol. 15, no 1, pp. 13-19.

Kuzcow M. (1979) The FTC and the Generic Doctrine: A New Rx for Pharmaceutical Trademarks, 15 Tulsa L. J. 327, p. 327-347. Available at: http://digitalcommons.law.utulsa.edu/cgi/viewcontent. cgi?article=1515\&context=tlr (accessed: 10.04.2016)

Mosback H. (2013) Protection of pharmaceutical trade marks in Europe: an overview, Journal of Intellectual Property Law \& Practice 8 (1), p. 69-77.

Pharmaceutical Trademarks 2013/2014: A Global Guide. Available at: http://www.worldtrademarkreview.com/Intelligence/Pharmaceutical-Trademarks/2013 (accessed: 10.04.2016)

Razumova G.V. (2012) Protivorechie obshchestvennym interesam kak osnovanie dlya otkaza v registratsii tovarnogo znaka [Contradicting Public Interests as a Reason to deny the Regisration of a Trademark]. Imushchestvennye otnosheniya v Rossiyskoy Federatsii, no 10. SPS Konsul'tantPlyus

Robinov A.A. (2013) Novoe v praktike Vysshego Arbitrazhnogo Suda Rossiyskoy Federatsii [New in the Practice of the RF Higher Arbitration Court]. Imushchestvennye otnosheniya v Rossiyskoy Federatsii, no 8. SPS Konsul'tantPlyus

Sadovskiy P., Demina M. (2015) Spory ob intellektual'noy sobstvennosti v sfere farmatsevtiki: poslednie tendentsii [Intellectual Property Disputes: Trends in Pharmaceutics]. Arbitrazhnye spory, no 1. SPS Konsul'tantPlyus

Schwartz V. E., Goldberg Ph., Silverman C. (2013) Warning: shifting liability to manufacturers of brandname medicines when the harm was allegedly caused by generic drugs has severe side effects, Fordham Law ReviewVol. 81, p. 1835-1879. Available at: http://fordhamlawreview.org/wp-content/uploads/ assets/pdfs/Vol_81/Schwartz_March.pdf (accessed: 10.04.2016)

Sim K. R., Robertson H. E. (2008) The Canadian Regime for Protecting Against Pharmaceutical Trademark Confusion and Mistakes, Trademark Reporter, The Law Journal of the International Trademark Association. Vol. 98 No. 5, p. 1253-1277. Available at: http://www.smart-biggar.ca/assets/tm_reporter_ vol98_no5.pdf (accessed: 10.04.2016)

Smith G. V. (1997) Trademark Valuation. N.Y.: John Wiley \& Sons, 293 p.

Williamson C. M. (2013) A Morphological Study of Drug Brand Names Honors Theses. Paper 104.

Zahl A. (2015) International Pharmaceutical Law and Practice, LexisNexis, 1280 p. 